\title{
Influencing Factors on the Choice of College Business School Major
}

\author{
Mitchell Franklin \\ Le Moyne College \\ Joan Myers \\ Le Moyne College \\ Greg Lepak \\ Le Moyne College
}

The purpose of this paper is to examine whether a variety of factors encountered by college students influence choice of college major for undergraduate business students. We examine factors including introductory courses, importance of professors, professor use of classroom resources, professor's discussion of career and future employment options, employment potential, future earnings potential as well as personal and family characteristics of a student. These findings will provide guidance for department chairs how to staff introductory courses, and professors who have the requisite work experience to emphasize future employment options and benefits of keeping families of students informed on the profession who have interested students.

Keywords: college major, college professors, business education

\section{INTRODUCTION}

The purpose of this study is to examine the impact of several factors on the influence of college major choice for undergraduate business students. We examine specific attributes of professors and other demographic factors to determine their impact on choice of college major. Department chairs as well as faculty members can utilize the results of this study to ensure:

1. That classes are properly staffed with faculty who possess the necessary skills to assist students in major selection, and

2. That academic programs also have efforts in place to manage and educate other parties who play a significant impact in the student major decision to ensure that students are provided with the proper information to ensure an informed decision is made.

\section{REVIEW OF LITERATURE}

Previous research has examined factors influencing choice of college major. Montmarquette, Cannings and Mahseredjian (2002) find that the choice of major depends on the expected earnings variable in that major compared to other majors offered. In an additional study, Pritchard, Potter and Saccucci (2004) 
examine factors that influence students' choice of a business major. The authors find that students with stronger quantitative skills were more likely to major in accounting or finance, and that students with weaker quantitative skills were more likely to major in marketing and management. Finally, Ersoy (2020) found that students' expectations regarding the future labor market are affected by local market conditions. Specifically, the author found that students shifted their choice of majors from recession-sensitive majors to recession-resistant majors after the Great Recession from 2007-2010.

Malgwi, Howe, and Burnaby, (2005) previously showed that interest in the major was the most important factor for incoming freshmen, regardless of gender. For women, the next most influential factor was aptitude in the subject. However, men were significantly more influenced by the major's potential for career advancement and job opportunities and the level of compensation in the field. When a student decided to change a major, the change was driven by opportunity in the new major as opposed to negative experiences in the prior major.

It is important to consider how a first-generation college student may examine the decision of college major. Chen (2005) shows that these students are at a significant disadvantage to obtain information that can be important in selection of a major. First generation students tend to gravitate to majors that tend to be considered by parents and high school counselors to be "vocational" but also have the greatest earnings potential. Chen (2005) does not discuss how students specifically become aware of earnings potential within a specific major.

Beffy, Fougere and Maurel (2012) as other authors, show that earnings potential is a determinant of major selection. Though potential earnings is one determinant, its relation is low compared to other factors that are consistent with the business cycle in France, where the study was conducted. This paper is consistent because it shows that factors that influence major choice may vary by country, but also that there are other factors that interact with earnings on choice of major.

Arcidiacono, Hotz, and Kang (2012) surveys students for their perception of earnings in their respective choice of major as well as counterfactual majors, as well as the student perception of their own ability to succeed within a specific major. The authors show that the students' perception of their own ability, as well as their own perception of future earnings, influence major decision. Wiswall and Zafar (2015) examine factors that influence the selection of a college major using a generated panel of beliefs. Based on the panel provided, students select their majors based on beliefs regarding their own heterogeneous tastes, with a weight correlated to earnings ability and perception of personal ability. Finally, Liu (2018) found that socioeconomic status affects choice of major. Students from lower income families had a greater tendency to choose a major from the social sciences other than Economics. Non-pecuniary factors played a larger role in their choice of majors, however expected future income was only significant for the lower income group. Parental approval was only significant for students from higher income families.

Arcidiacono, Hotz, and Kang (2012) and Wiswall and Zafar (2015) are significant as they both are based on student perceptions of their own ability and earnings. It is important to question the accuracy of these student perceptions. A first-generation college student might lack the appropriate resources to accurately assess earnings potential within a specific professional career relative to a student who has parents that are professionals within a related field. Additionally, one needs to question how accurately a student can measure their own ability based on factors presented within Chen (2005).

Similarly, Pappu (2004) conducts a survey on factors influencing undergraduate marketing majors choice of marketing as their college major. The author finds that important factors, including marketing is easily combined with other business majors, marketing was perceived to provide useful information in running a business, marketing concepts are practical and widely applicable in business settings, exposure to introductory marketing courses in the early stages of an undergraduate program, diversity in the offerings of a marketing program and a wide variety of career prospects and reputation of academics in the school. Stice, Swain and Worsham (1997) survey students on the first day of an introductory accounting course and at the end of the course and examine how performance affects a "qualified" student's decision to major in accounting. The authors analyze students' work experience, high school accounting, ACT score and performance on the midterm exam and find that students with a high aptitude for accounting did not consider their performance in the first accounting class when choosing accounting as a major. Taylor and 
Popma (1990) examine differences between students that selected an academic major or career choice, had made a tentative selection, or had not decided. The authors found that students who selected a major/career choice had greater career decision-making self-efficacy, career salience and lower vocational indecision. Wilhelm (2004) identified instructor attributes that were important for business majors selecting courses. The author found that course worth/usefulness, and grading leniency were the most important factors influencing course selection. Instructor evaluations were also an important influence.

Theoretical research has also examined choice of college major. Strasser, Ozgur and Schroeder (2002) develop a model of how students choose a major using the Analytical Hierarchy Process. This model is based on the decision criteria that the students utilized in making their choice of major. It requires students to compare majors based on different criteria and rank the relative importance of those criteria. The model predicted students' first choice major with 88 percent accuracy for both sophomores as well as seniors. As expected, sophomores were more inconsistent in their selection than seniors. The authors also find that students clustered majors into two distinct groups; one group included accounting, finance and decision science majors while the other group included marketing and management majors.

Kumar and Kumar (2013) also develop a model that can be used to predict what factors lead to specific major declaration in business schools. Social image, job availability, and aptitude were found to be significant factors that impact students' decisions to select a business major. The results also reveal that family, high-school counselors, and professors have a major influence on students' decisions. Furthermore, some unique differences were found related to gender and decided/undecided status of students. Choi, Lou and Mukherjee (2017) found that extreme newsworthy events in an industry were associated with a disproportionately higher number of students majoring in fields related to the industry. Zafar (2013) specifically examines gender to show that the enjoyment of coursework and parental approval are the most important determinants in the choice for both genders. However, males and females differ in their preferences in the workplace, with males caring about the pecuniary outcomes in the workplace much more than females. Porter and Serra (2020) found that having positive Economics alumni as role models in the field was found to have a significant effect on female students' enrollment in upper level classes and in their likelihood to major in economics.

Granitz, Chen, and Kohli (2014) examine students at the high school level to determine what factors at that level drive major, before the students arrive on a college campus, or make a decision on attending college. Students still in high school are most likely to rely on parents for guidance and influence in this decision. In the case of a first-generation college student, there is a high probability that this information as relied on by students may not be accurate and lead to students making unwise college decisions and changing their major once they arrive at college and are influenced by different factors.

Our study contributes to the literature in that we examine specific attributes that may affect the decision to choose one major over another. Our survey of senior students includes questions on professor enthusiasm, professor knowledge of material, professor's discussion of career and future employment options and an interactive classroom environment as what was a factor when they declared their major. Though earnings and perception of ability is a common trend, research shows interaction of earnings and other measures. This paper examines the interaction of several variables together to more accurately provide guidance of relationship of several variables together to predict major, as shown as significant in France by Beffy, Fougere and Maurel (2012). This paper also validates many of the variables predicted within the theoretical models presented within this paper. We combine our predictions into the following hypotheses:

H1: The importance of earnings potential of the field impacts students' choice of major.

H2: The importance of the influence of high school teachers and guidance counselors impacts students' choice of major.

H3: The importance placed on the influence of professors' discussions about career opportunities impacts students' choice of major. 


\section{H4: The importance placed on students' gender impacts students' choice of major.}

This study contributes to the literature by addressing these questions in a more current era than the previous studies in the literature review. Many of these studies were from the late 1990's and early 2000's, when information from the Internet and social media was not as readily accessible by students. Thus, parents, high school teachers and guidance counselors may have had more influence on their decisions than current information about career opportunities. Even the most recent article by Ersoy (2020) focused on the impact on the recessionary time from 2007-2010 on the choice of college major. Most current students would not remember, nor be influenced by, an economic crisis of a decade earlier. Economic conditions have changed; therefore, earnings potentials of various career paths may have changed. Information access has transformed, which may impact the degree to which people in students' lives impact their choice of college major. Finally, our research was conducted in a small, liberal arts based, comprehensive college. Many of the students in attendance are first generation college students. This factor may also impact the students' choice of college major.

\section{DATA ANALYSIS}

The objective of this study is to examine the perceptions of senior business students regarding the factors that may influence their choice of primary business major. Results from focus group meetings of professionals in education as well as from relevant literature were used to construct a survey instrument with questions that addressed choice of major. Data were obtained on several variables that may influence choice of primary major from seniors enrolled in a capstone course during one semester in a business school at a small, private AACSB accredited college. Because of limited sample sizes for several of the majors reported as being primary, this study reports the effects of nine variables on choice of primary business major for three highly populated majors at the business school. Data from forty-four completed survey forms were used in our statistical analyses.

The business majors considered in this study are accounting (ACT), finance (FIN), and marketing (MKT). Sample respondents were asked to rate the influence of seven variables on their choice of a primary business major: "potential to obtain a job" (PJ); "future earnings potential" (FEP); "discussion by professor of career and future employment options" (CFEO); "interactive classroom environment" (ICE); "introductory course in major" (ICM); "high school teachers" (HST); and "guidance counselors" (GC). The variables were quantified using a six-point Likert scale (zero $=$ did not influence to five $=$ strong influence). In addition, respondents provided information on their gender and race. Indicator variables are used to code these demographic variables: $($ one $=$ male, zero $=$ female) for gender and (one $=$ persons of color, zero $=$ white/European American) for race.

\section{Methodology}

Multinomial logistic regression is used to investigate the factors that influence the choice of a primary business major. Using conventional notation, let $Y_{i}$ represent a nominal response with $K$ unordered categories (arbitrarily labeled $1, \ldots, K$ ) for the ith subject, $i=1, \ldots, n$. In general, there can be one or more explanatory variables associated with each response. The methodology pairs each response category with a baseline or reference category. The notation used here labels category $K$ as the baseline category; however, any category may be labeled $K$. Defining $P\left(Y_{i}=k\right)$ as the multinomial probability of a response falling in the kth category, the objective is to obtain the relationship between $P\left(Y_{i}=k\right)$ and the explanatory variables. Using the log odds scale, a baseline category logistic model with $p$ explanatory variables can be represented as:

$$
\log \left\{\frac{P\left(Y_{i}=k\right)}{P\left(Y_{i}=K\right)}\right\}=\alpha_{k}+\beta_{k 1} X_{i 1}+\beta_{k 2} X_{i 2}+\cdots+\beta_{k p} X_{i p} \quad, \quad \text { for } k=1, \ldots, K-1
$$


The baseline category logistic model jointly fits the $K-1$ logistic regression models by maximizing the multinomial likelihood for the nominal responses. The log odds for all pairwise comparisons can be determined from this model.

\section{Analysis and Results}

Of the forty-four sample respondents in this study, the number of respondents who reported a primary major in accounting, finance, and marketing are ten, eighteen, and sixteen, respectively. The side-by-side boxplots in Figure 1 gives evidence that the distributions for some variables may be different for the three majors.

\section{FIGURE 1}

BOXPLOTS FOR VARIABLES MEASURED ON A LIKERT SCALE
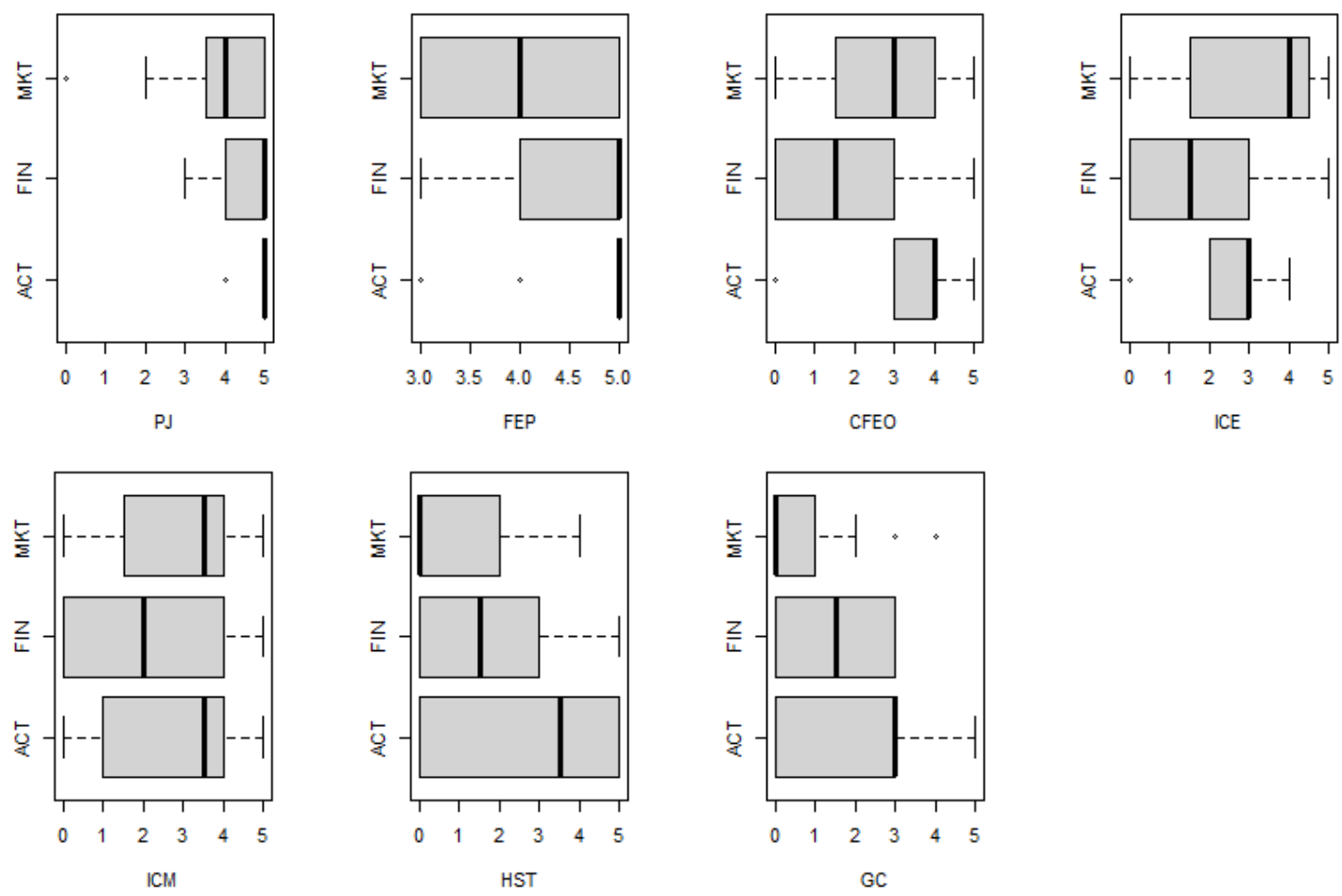

The multinomial logistic regression model in (eq. 1) with a single explanatory variable was estimated separately for each variable measured on a Likert scale using different majors as the baseline category. Table 1 presents the results for the effect of each variable on choice of primary business major.

Table 1(a) shows evidence that the estimated coefficient for the effect of "potential to obtain a job" for logit (ACT/MKT) is significantly different from zero (confidence limits do not include zero). Given that the choice of major is accounting or marketing, the estimated coefficient for job potential indicates that as this variable becomes more influential in the decision to choose a primary business major, students are relatively more likely (odds are higher) to choose accounting rather than marketing as a major. In addition, likelihood-ratio testing gives evidence for the effect of "potential to obtain a job" on choice of primary business major ( $p=0.011)$, i.e. there is evidence of a "potential to obtain a job" effect in at least one of the logits. The estimated coefficients for this variable for logit(FIN/MKT) and logit(ACT/MKT) are not significantly different from zero (confidence limits include zero).

Results for both logit(ACT/MKT) and logit(FIN/MKT) in Table 1(b) show that there is a preference for students to major in both accounting and finance rather than Marketing as the influence of "future earnings potential" increases (confidence intervals for the effects do not include zero). Likelihood-ratio 
testing also gives support that choice of primary business major is associated with "future earning potential" $(p=0.037)$. The estimated coefficient for "future earnings potential" for logit(ACT/FIN) is not significantly different from zero at the 0.05 level (confidence interval contains zero).

The results for Table 1(c) indicate that higher scores for the influence of "professor discussing career and future employment options" on choice of primary business major increase the odds of selecting Accounting rather than Finance as a major (confidence limits for this effect do not include 0). Likelihood ratio testing supports the lack of independence between this variable and choice of primary business major $(p=0.024)$. Accordingly, a unit increase on the Likert scale for this variable increases the odds of majoring in accounting rather than finance multiplicatively by a factor of 1.92 . The estimated effects for $\operatorname{logit}(\mathrm{ACT} / \mathrm{MKT}$ ) and logit(FIN/MKT) are not significantly different from zero (confidence limits include zero).

There is some evidence in Table 1(d) that "interactive learning environment" is associated with choice of primary business major. The estimated coefficient for the effect of "interactive learning environment" on choice of primary business major for logit(FIN/MKT) is significantly different from zero at the 0.05 level (confidence limits do not include zero). The negative coefficient for this effect implies that students are relatively more likely to choose marketing rather than finance as a major when the influence of "interactive learning environment" on choice of major increases. However, likelihood ratio testing gives weaker support for this result $(p=0.081)$. The effects of this variable for both logit(ACT/MKT) and $\operatorname{logit}(\mathrm{ACT} / \mathrm{FIN}$ ) are not significant at the 0.05 level (confidence limits include zero).

Table 1(e) gives no evidence for the preference of one major versus another major as students place more weight on the value of a major's introductory course in influencing their choice for a primary business major. The confidence interval measuring the effect of "introductory course in major" for each logit in Table 1(e) contains zero, and likelihood ratio testing does not support a relationship between this variable and choice of primary business major.

The logits for estimating the effect of "high school teachers" on choice of primary business major are given in Table 1(f). A significant effect for this variable is reported for logit(ACT/MKT) in Table 1(f). If the choice of primary major is accounting or marketing, students prefer Accounting rather than Marketing when the influence of their high school teachers on their choice of major increases (confidence interval does not contain zero). This effect is supported by likelihood ratio testing $(p=0.019)$. There are no significant effects for this variable for logit(FIN/MKT) and logit(ACT/FIN).

Table 1(f) shows the results for estimating the effect of "guidance counselors" on choice of primary business major. For logit(ACT/MKT), accounting rather than marketing is the preferred major when the influence of "guidance counselors" on selecting a college primary business major increases. Likelihood ratio testing, comparing the maximized likelihood for one model that constrains all the $\beta^{\prime} s$ in (1) to be zero versus the maximized likelihood for a nested model without the constraints, supports this result $(p=$ 0.039). There are no significant effects for this variable for logit(FIN/MKT) and logit(ACT/FIN). 


\section{TABLE 1}

MULTINOMIAL LOGISTIC REGRESSION RESULTS FOR SELECTED EXPLANATORY VARIABLES

\begin{tabular}{|c|c|c|c|c|c|}
\hline \multirow{3}{*}{$\begin{array}{l}\text { (a) } \\
\text { Logit }\end{array}$} & \multicolumn{5}{|c|}{ Effect of "Potential to Obtain a Job" on Choice of Primary Major } \\
\hline & \multirow[b]{2}{*}{ Coef. } & \multirow[b]{2}{*}{ s.e. } & \multirow[b]{2}{*}{ p-value } & \multicolumn{2}{|c|}{$95 \%$ C.I. } \\
\hline & & & & Lower & Upper \\
\hline \multicolumn{6}{|c|}{ Logit (ACT/MKT) } \\
\hline Constant & -10.562 & 5.288 & & & \\
\hline JP & 2.181 & 1.092 & 0.046 & 0.51 & 5.15 \\
\hline \multicolumn{6}{|c|}{ Logit (FIN/MKT) } \\
\hline Constant & -2.814 & 1.974 & & & \\
\hline $\mathrm{JP}$ & 0.680 & 0.443 & 0.125 & -0.06 & 1.70 \\
\hline \multicolumn{6}{|c|}{$\operatorname{Logit}(\mathrm{ACT} / \mathrm{FIN})$} \\
\hline Constant & -7.748 & 5.278 & & & \\
\hline JP & 1.500 & 1.083 & 0.166 & -0.21 & 4.45 \\
\hline Likelihood I & & & 0.011 & & \\
\hline
\end{tabular}
(b)

Effect of "Future Earnings Potential" on Choice of Primary Major Coef. s.e. $\quad$-value $95 \%$ C.I.

\begin{tabular}{lccccc} 
Logit & Coef. & s.e. & p-value & Lower & Upper \\
\hline Logit (ACT/MKT) & & & & & \\
$\quad$ Constant & -6.140 & 2.975 & & 0.15 & 2.79 \\
$\quad$ FEP & 1.291 & 0.649 & 0.047 & & \\
Logit (FIN/MKT) & & & & 0.04 & 1.93 \\
$\quad$ Constant & -3.833 & 2.074 & & & \\
$\quad$ FEP & 0.920 & 0.473 & 0.052 & & \\
Logit (ACT/FIN) & & & & & \\
$\quad$ Constant & -2.307 & 3.086 & & \\
$\quad$ FEP & 0.371 & 0.657 & 0.572 & & \\
Likelihood Ratio Test: & & & 0.037 & & \\
\hline
\end{tabular}
(c)

Effect of "Discussion by Professor of Career and Future Employment Options" on Choice of Primary Major

\begin{tabular}{|c|c|c|c|c|c|}
\hline \multirow[b]{2}{*}{ Logit } & \multirow[b]{2}{*}{ Coef. } & \multirow[b]{2}{*}{ s.e. } & \multirow[b]{2}{*}{ p-value } & \multicolumn{2}{|c|}{$95 \%$ C.I. } \\
\hline & & & & Lower & Upper \\
\hline \multicolumn{6}{|l|}{ Logit (ACT/MKT) } \\
\hline Constant & -1.411 & 1.016 & & & \\
\hline CFEO & 0.296 & 0.282 & 0.293 & -0.22 & 0.92 \\
\hline \multicolumn{6}{|l|}{ Logit (FIN/MKT) } \\
\hline Constant & 0.923 & 0.597 & & & \\
\hline CFEO & -0.354 & 0.205 & 0.084 & -0.78 & 0.03 \\
\hline \multicolumn{6}{|l|}{ Logit (ACT/FIN) } \\
\hline Constant & -2.334 & 0.968 & & & \\
\hline CFEO & 0.650 & 0.283 & 0.022 & 0.15 & 1.29 \\
\hline Likelihood Ratio Test: & & & 0.024 & & \\
\hline
\end{tabular}




\begin{tabular}{|c|c|c|c|c|c|}
\hline \multirow{2}{*}{$\begin{array}{l}\text { (d) } \\
\text { Logit }\end{array}$} & \multicolumn{5}{|c|}{$\begin{array}{l}\text { Effect of "Interactive Classroom Environment" on Choice of Primary Major } \\
95 \% \text { C.I. }\end{array}$} \\
\hline & Coef. & s.e. & $\mathrm{p}$-value & Lower & Upper \\
\hline \multicolumn{6}{|l|}{ Logit (ACT/MKT) } \\
\hline Constant & 0.173 & 0.769 & & & \\
\hline ICE & -0.235 & 0.242 & 0.333 & -0.73 & 0.24 \\
\hline \multicolumn{6}{|l|}{ Logit (FIN/MKT) } \\
\hline Constant & 1.225 & 0.652 & & & \\
\hline ICE & -0.460 & 0.217 & 0.034 & -0.92 & -0.06 \\
\hline \multicolumn{6}{|l|}{ Logit (ACT/FIN) } \\
\hline Constant & -1.052 & 0.638 & & & \\
\hline ICE & 0.226 & 0.230 & 0.328 & -0.22 & 0.70 \\
\hline Likelihood Ratio Test: & & & 0.081 & & \\
\hline (e) & \multicolumn{5}{|c|}{$\begin{array}{c}\text { Effect of "Introductory Course in a Major" on Choice of Primary Major } \\
95 \% \text { C.I. }\end{array}$} \\
\hline Logit & Coef. & s.e. & $\mathrm{p}$-value & Lower & Upper \\
\hline \multicolumn{6}{|l|}{ Logit (ACT/MKT) } \\
\hline Constant & -0.431 & 0.807 & & & \\
\hline ICM & -0.013 & 0.240 & 0.956 & -0.49 & 0.48 \\
\hline \multicolumn{6}{|l|}{ Logit (FIN/MKT) } \\
\hline Constant & 0.938 & 0.618 & & & \\
\hline ICM & -0.339 & 0.204 & 0.096 & -0.76 & 0.05 \\
\hline \multicolumn{6}{|l|}{ Logit (ACT/FIN) } \\
\hline Constant & -1.369 & 0.723 & & & \\
\hline $\mathrm{ICM}$ & 0.325 & 0.233 & 0.163 & -0.12 & 0.82 \\
\hline Likelihood Ratio Test: & & & 0.165 & & \\
\hline (f) & \multicolumn{5}{|c|}{ Effect of "High School Teachers" on Choice of Primary Major } \\
\hline Logit & Coef. & s.e. & $\mathrm{p}$-value & Lower & Upper \\
\hline \multicolumn{6}{|l|}{ Logit (ACT/MKT) } \\
\hline Constant & -1.727 & 0.705 & & & \\
\hline HST & 0.660 & 0.259 & 0.014 & 0.19 & 1.22 \\
\hline \multicolumn{6}{|l|}{ Logit (FIN/MKT) } \\
\hline Constant & -0.198 & 0.436 & & & \\
\hline HST & 0.252 & 0.218 & 0.248 & -0.16 & 0.71 \\
\hline \multicolumn{6}{|l|}{ Logit (ACT/FIN) } \\
\hline Constant & -1.530 & 0.707 & & & \\
\hline HST & 0.409 & 0.228 & 0.073 & -0.02 & 0.90 \\
\hline Likelihood Ratio Test: & & & 0.019 & & \\
\hline
\end{tabular}




\begin{tabular}{|c|c|c|c|c|c|}
\hline \multirow{3}{*}{$\begin{array}{l}(\mathrm{g}) \\
\text { Logit }\end{array}$} & \multicolumn{5}{|c|}{ Effect of "Guidance Counselors" on Choice of Primary Major } \\
\hline & \multirow[b]{2}{*}{ Coef. } & \multirow[b]{2}{*}{ s.e. } & \multirow[b]{2}{*}{$\mathrm{p}$-value } & \multicolumn{2}{|c|}{95 \% C.I. } \\
\hline & & & & Lower & Upper \\
\hline \multicolumn{6}{|c|}{ Logit (ACT/MKT) } \\
\hline Constant & -1.593 & 0.681 & & & \\
\hline $\mathrm{GC}$ & 0.746 & 0.318 & 0.019 & 0.16 & 1.43 \\
\hline \multicolumn{6}{|c|}{ Logit (FIN/MKT) } \\
\hline Constant & -0.202 & 0.445 & & & \\
\hline GC & 0.302 & 0.270 & 0.263 & -0.21 & 0.87 \\
\hline \multicolumn{6}{|c|}{ Logit (ACT/FIN) } \\
\hline Constant & -1.391 & 0.683 & & & \\
\hline $\mathrm{GC}$ & 0.444 & 0.281 & 0.115 & -0.08 & 1.05 \\
\hline Likelihood I & & & 0.039 & & \\
\hline
\end{tabular}

Table 2 gives the number of respondents in each major for the four race/gender combinations. The same model building and inferential procedures were used to measure the effects of gender and race on choice of primary major. The multinomial logistic regression model in (eq. 1) with both gender and race as explanatory variables was estimated using different majors as the baseline category. Table 3 gives the estimated log odds ratios for selected pairs of majors for this model. Results of likelihood ratio testing in Table 3(a) give evidence that gender has a significant effect on choice of primary business major ( $p=$ $0.021)$; in contrast, the variable for race can be dropped from the model $(p=0.610)$.

Table 3(b) shows an estimated multinomial logistic regression model using gender as the single explanatory variable. The estimated effect parameter for gender in logit(FIN/MKT) implies that for male respondents, the estimated odds of a Finance major versus a Marketing major are 8.33 times those for female respondents. This is a statistically significant result at the 0.05 level of significance (confidence interval does not include zero). A likelihood ratio test for this working model versus a null model with a constant indicates that gender has a significant effect on choice of major $(p=0.037)$. There are no significant gender effects for logit(ACT/MKT) and logit(ACT/FIN).

Finally, estimated probabilities for the three majors are given in Table 4. According to the model fit, females are most likely to major in Marketing; however, males are most likely to select Finance as a major.

TABLE 2

NUMBER OF RESPONDENTS IN EACH MAJOR BY RACE AND GENDER

\begin{tabular}{llccc}
\hline Race & Gender & Accounting & Finance & Marketing \\
\hline White/European American & Female & 4 & 3 & 7 \\
& Male & 5 & 13 & 5 \\
\multirow{3}{*}{ Persons of Color } & & & & 3 \\
& Female & 1 & 0 & 1 \\
\hline
\end{tabular}


TABLE 3

MULTINOMIAL LOGISTIC REGRESSION RESULTS FOR CHOICE OF MAJOR USING GENDER AND RACE AS EXPLORATORY VARIABLES

\begin{tabular}{|c|c|c|c|c|c|}
\hline \multirow{2}{*}{$\begin{array}{l}\text { (a) } \\
\text { Logit }\end{array}$} & \multirow[b]{2}{*}{ Coef. } & \multirow[b]{2}{*}{ s.e. } & \multirow[b]{2}{*}{$\mathrm{p}$-value } & mary M & \\
\hline & & & & Lower & Upper \\
\hline \multicolumn{6}{|l|}{ Logit (ACT/MKT) } \\
\hline Constant & -0.487 & 0.589 & & & \\
\hline Gender: Male & 0.433 & 0.828 & 0.601 & -1.20 & 2.09 \\
\hline Race: POC & -1.041 & 1.209 & 0.390 & -4.11 & 1.10 \\
\hline \multicolumn{6}{|l|}{ Logit (FIN/MKT) } \\
\hline Constant & -1.044 & 0.691 & & & \\
\hline Gender: Male & 2.061 & 0.823 & 0.012 & 0.54 & 3.83 \\
\hline Race: POC & -0.720 & 1.042 & 0.490 & -2.95 & 1.31 \\
\hline \multicolumn{6}{|l|}{ Logit (ACT/FIN) } \\
\hline Constant & 0.557 & 0.756 & & & \\
\hline Gender: Male & -1.628 & 0.899 & 0.070 & -3.52 & 0.08 \\
\hline Race: POC & -0.321 & 1.345 & 0.812 & -3.54 & 2.24 \\
\hline \multicolumn{3}{|c|}{ Likelihood Ratio Test: (model without gender) } & 0.021 & & \\
\hline \multicolumn{3}{|c|}{ Likelihood Ratio Test: (model without race) } & 0.610 & & \\
\hline \multirow[t]{2}{*}{ (b) } & \multicolumn{5}{|c|}{ Effect of Gender on Choice of Primary Major } \\
\hline & & & & & \\
\hline Logit & Coef. & s.e. & p-value & Lower & Upper \\
\hline \multicolumn{6}{|l|}{ Logit (ACT/MKT) } \\
\hline Constant & -0.693 & 0.548 & & & \\
\hline Gender:Male & 0.511 & 0.817 & 0.532 & -1.10 & 2.15 \\
\hline \multicolumn{6}{|l|}{ Logit (FIN/MKT) } \\
\hline Constant & -1.204 & 0.658 & & & \\
\hline Gender:Male & 2.120 & 0.817 & 0.009 & 0.61 & 3.88 \\
\hline \multicolumn{6}{|l|}{ Logit (ACT/FIN) } \\
\hline Constant & 0.511 & 0.730 & & & \\
\hline Gender:Male & -1.609 & 0.894 & 0.072 & -3.490 & 0.096 \\
\hline Likelihood Ratio & & & 0.037 & & \\
\hline
\end{tabular}

TABLE 4

ESTIMATED PROBABILITIES FOR MAJORS BY GENDER

\begin{tabular}{lccc}
\hline Gender & Accounting & Finance & Marketing \\
\hline Female & 0.278 & 0.167 & 0.556 \\
Male & 0.192 & 0.577 & 0.231 \\
\hline
\end{tabular}

\section{SUMMARY AND CONCLUSION}

If the choice of primary business major is accounting or marketing, students are more likely to choose Accounting rather than Marketing when the potential to obtain a job as well as future earnings potential become more influential in their decision to choose a major. Students also prefer accounting versus marketing when the influence of their high school teachers and guidance counselors on their choice of major increases. When comparing the Finance and Marketing majors, Finance is the preferred major as future 
earnings potential increases in importance; on the other hand, there is some evidence that Marketing is preferred as students place more importance on a curriculum that emphasizes an interactive learning environment. Students are also more likely to choose Accounting over Finance as the influence of classroom discussions by professors about career and future employment options on their choice of major increases. Finally, results of this study's demographic analyses show that gender has a significant effect on choice of primary business major; for male respondents, the odds of a Finance major versus a Marketing major are significantly higher than those for female respondents. Results of a gender effect were not found when comparing Accounting with Marketing and Accounting with Finance.

Faculty within each major need to develop an understanding of factors that influence majors within their area, and develop appropriate recruitment strategies that are based on those factors. It is likely that when relevant factors are used to target students, retention and student success will increase. For future research, this study needs to be replicated with a larger sample at multiple schools to realize a better understanding of the associations that exist between selected factors and choice of major.

There are several suggestions for future research resulting from this study. First, the survey should be conducted again to increase sample size. With greater sample size, more majors could be included in the study's analysis. In addition, it should be conducted at earlier levels in the college educational process to determine if the influences on choice of major are consistent across the students' educational level or not. Future research will include factors related to students' backgrounds. The educational levels of students' parents were not included in this study. Although previous studies investigated parental approval, they did not include questions on parental education, which could either expand students' options or limit them. Finally, more demographic data could be collected and incorporated into the model, such as information on the high school attended, SAT scores, and participation in activities.

\section{REFERENCES}

Arcidiacono, P., Hotz, V.J., \& Kang, S. (2012). Modeling college major choices using elicited measures of expectations and counterfactuals. Journal of Econometrics, 166(1), 3-16.

Beffy, M., Fougere, D., \& Maurel, A. (2012). Choosing the field of study in postsecondary education: Do expected earnings matter? Review of Economics and Statistics, 94(1), 334-347.

Chen, X. (2005). First-generation students in postsecondary education: A look at their college transcripts.

Choi, D., Lou, D., \& Mukherjee, A. (2017, September). The effect of superstar firms on college major choice. Centre for Economic Policy Research. Retrieved from

Cepr.org/active/publications/discussion_papers.php?dpno=12296

Ersoy, F. (2020, July 11). The effects of the great recession on college majors. Economics of Education Review, 77. Retrieved from www.elsevier.com/locate/econedurev

Granitz, N., Chen, S., \& Kohli, K.K. (2014). Choosing business as a college major: A survey of high school students. Journal of the Academy of Business Education, 15(1).

Kumar, A., \& Kumar, P. (2013). An examination of factors influencing students selection of business majors using TRA framework. Decision Sciences Journal of Innovative Education, 11(1), 77 105.

Liu, X. (2018, June 15). College major choice under financial constraint: How do low-income students choose majors compared to the representative body at Northwestern? Dissertation: Mathematical Methods on the Social Sciences and Economics. Retrieved from mmss.wcas.northwestern.edu

Malgwi, C.A., Howe, M.A., \& Burnaby, P.A. (2005). Influences on students' choice of college major. Journal of Education for Business, 80(5), 275-282.

Montmarquette, C., Cannings, K., \& Mahseredjian, S. (2002). How do young people choose college majors? Economics of Education Review, 21(6), 543-556.

Pappu, R. (2004). Why do undergraduate marketing majors select marketing as a business major? Evidence from Australasia. Journal of Marketing Education, 26(1), 31-41.

Porter, C., \& Serra, D. (2020). Gender differences in the choice of major: The importance of female role models. American Economic Journal: Applied Economics, 12(3), 226-54. 
Pritchard, R., Potter, G., \& Saccucci, M. (2004). The selection of a business major: Elements influencing student choice and implications for outcomes assessment. Journal of Education for Business, $79(3), 152-156$.

Stice, J., Swain, M., \& Worsham, R. (1997). The effect of performance on the decision to major in accounting. Journal of Education for Business, 73(1), 54-57.

Strasser, S., Ozgur, C., \& Schroeder, D. (2002). Selecting a business college major: An analysis of criteria and choice using the analytical hierarchy process. Mid-American Journal of Business, 17(2), 4756.

Taylor, K., \& Popma, J. (1990). An examination of the relationships among career decision-making selfefficacy, career salience, locus of control, and vocational indecision. Journal of Vocational Behavior, 37(1), 17-31.

Wilhelm, W. (2004). The relative influence of published teaching evaluations and other instructor attributes on course choice. Journal of Marketing Education, 26(1), 17-30.

Wiswall, M., \& Zafar, B. (2015). Determinants of college major choice: Identification using an information experiment. The Review of Economic Studies, 82(2), 791-824.

Zafar, B. (2013). College major choice and the gender gap. Journal of Human Resources, 48(3), 545-595. 